\title{
Mechanisms of haptoglobin protection against hemoglobin peroxidation triggered endothelial damage
}

\author{
CA Schaer ${ }^{1,6}$, JW Deuel ${ }^{2,6}$, AG Bittermann $^{3}$, IG Rubio ${ }^{4}$, G Schoedon ${ }^{2}$, DR Spahn ${ }^{1}$, RA Wepf ${ }^{3}$, F Vallelian ${ }^{2}$ and DJ Schaer ${ }^{\star 2,5}$
}

Extracellular hemoglobin $(\mathrm{Hb})$ has been recognized as a disease trigger in hemolytic conditions such as sickle cell disease, malaria, and blood transfusion. In vivo, many of the adverse effects of free $\mathrm{Hb}$ can be attenuated by the $\mathrm{Hb}$ scavenger acutephase protein haptoglobin $(\mathrm{Hp})$. The primary physiologic disturbances that can be caused by free $\mathrm{Hb}$ are found within the cardiovascular system and $\mathrm{Hb}$-triggered oxidative toxicity toward the endothelium has been promoted as a potential mechanism. The molecular mechanisms of this toxicity as well as of the protective activities of $\mathrm{Hp}$ are not yet clear. Within this study, we systematically investigated the structural, biochemical, and cell biologic nature of $\mathrm{Hb}$ toxicity in an endothelial cell system under peroxidative stress. We identified two principal mechanisms of oxidative $\mathrm{Hb}$ toxicity that are mediated by globin degradation products and by modified lipoprotein species, respectively. The two damage pathways trigger diverse and discriminative inflammatory and cytotoxic responses. Hp provides structural stabilization of $\mathrm{Hb}$ and shields $\mathrm{Hb}$ 's oxidative reactions with lipoproteins, providing dramatic protection against both pathways of toxicity. By these mechanisms, $\mathrm{Hp}$ shifts $\mathrm{Hb}$ 's destructive pseudo-peroxidative reaction to a potential anti-oxidative function during peroxidative stress.

Cell Death and Differentiation (2013) 20, 1569-1579; doi:10.1038/cdd.2013.113; published online 30 August 2013

Extracellular hemoglobin $(\mathrm{Hb})$ has multiple biological activities that can initiate and exacerbate disease processes. ${ }^{1}$ In acquired and genetic hemolytic anemias, malaria, massive blood transfusions, and severe infections, the presence of free $\mathrm{Hb}$ appears to cause endothelial dysfunction, vascular damage, and inflammation. ${ }^{2}$ More-localized effects of extracellular $\mathrm{Hb}$ are relevant during the initiation and propagation of atherosclerosis and in the regulation of inflammation and wound healing. ${ }^{3,4}$

During mild hemolysis, $\mathrm{Hb}$ and heme scavenger plasma proteins attenuate the adverse effects of extracellular $\mathrm{Hb}{ }^{1}$ Haptoglobin $(\mathrm{Hp})$ binds extracellular $\mathrm{Hb}$ to form an irreversible complex that can be cleared by CD163positive monocytes and macrophages., ${ }^{5,7}$ Preclinical studies have suggested a strong therapeutic potential for $\mathrm{Hp}$ infusion in conditions with enhanced intravascular hemolysis. ${ }^{8,9}$ Within the $\mathrm{Hb} / \mathrm{Hp}$ complex, the inherent vasoactivity of free $\mathrm{Hb}$ remains controlled, its redox reactivity is stabilized, and $\mathrm{Hb}$ itself is protected against oxidative damage. $8,10,11$

On a molecular level, the pathophysiology of $\mathrm{Hb}$ is generally explained by its side reactions. ${ }^{1}$ Among these reactions, depletion of the vasodilator nitric oxide (NO) and its reaction with hydrogen peroxide $\left(\mathrm{H}_{2} \mathrm{O}_{2}\right)$ are the most extensively studied. $\mathrm{H}_{2} \mathrm{O}_{2}$ is produced by nicotinamide adenine dinucleotide phosphate oxidases at supra-physiological levels upon tissue damage by resident tissue cells (i.e., epithelial cells) and during the subsequent inflammatory reaction by invading leukocytes. ${ }^{12,13,14}$ However, although NO depletion and associated endothelial dysfunction is now an accepted pathophysiologic model, a set of cohesive mechanistic concepts that link the oxidative side reactions of $\mathrm{Hb}$ to adverse cellular and physiologic responses is still lacking. Specifically, gaps in our knowledge remain concerning the mechanisms that link the primary biochemical processes (i.e., the reactions of $\mathrm{Hb}$ with $\mathrm{H}_{2} \mathrm{O}_{2}$ ) with the reaction intermediates, final effectors, and pathways that ultimately determine cellular- and tissue-level damage. Accordingly, the mechanisms by which $\mathrm{Hp}$ could protect against oxidative $\mathrm{Hb}$ toxicity are not clear. The current theories causally relate oxidative $\mathrm{Hb}$ toxicity and $\mathrm{Hp}$ protection to diverse mechanisms even in the absence of strong biological evidence. ${ }^{11,15,16,17,18,19,20}$

In this study, we utilized a systematic approach to characterize Hp-attenuated reaction species that could

\footnotetext{
${ }^{1}$ Institute of Anesthesiology, University Hospital, Zurich, Switzerland; ${ }^{2}$ Division of Internal Medicine, University Hospital, Zurich, Switzerland; ${ }^{3}$ Electron Microscopy Center (EMEZ), ETH Zurich, Switzerland; ${ }^{4}$ Laboratory of Physical Chemistry, ETH Zurich, Switzerland and ${ }^{5}$ Center for Evolutionary Medicine (ZEM), University of Zurich, Zurich, Switzerland

${ }^{*}$ Corresponding author: DJ Schaer, Division of Internal Medicine, University Hospital, CH-8091, Zurich, Switzerland. Tel: +41 442551111 ; E-mail: dominik.schaer@usz.ch

${ }^{6}$ These authors contributed equally to this work.

Keywords: hemoglobin; haptoglobin; peroxidation; endothelial damage

Abbreviations: $\mathrm{XLHb}, \alpha-\alpha$-cross-linked human $\mathrm{Hb}$; ATF3, activating transcription factor 3; bvHb, bovine $\mathrm{Hb}$; CLEM, correlative light-electron microscopy; DAPI, 4,6diamidino-2-phenylindole; DBBF, bis(3,5-dibromosalicyl)fumarate; DEPMPO, 5-(diethoxyphosphoryl)-5-methyl-1-pyrroline- $\mathrm{N}$-oxide; ECIS, electric cell-substrate impedance sensing; EPR, electron paramagnetic resonance; FIB/SEM, focused ion beam-scanning electron microscopy; FLM, fluorescence light microscopy; GOX, glucose oxidase; $\mathrm{H}_{2} \mathrm{O}_{2}$, hydrogen peroxide; $\mathrm{Hb}$, hemoglobin; $\mathrm{HLMVEC}$, human lung microvascular endothelial cell; $\mathrm{HLyEC}$, human lymphatic endothelial cell; $\mathrm{HO}-1$, heme oxygenase $1 ; \mathrm{Hp}$, haptoglobin; HPAEC, human pulmonary artery endothelial cell; Hpx, hemopexin; HUVEC, human umbilical vein endothelial cell; ITO, indium-tinoxide; LDL, low-density lipoprotein; mRNA, messenger ribonucleic acid; NO, nitric oxide; PBS, phosphate-buffered saline; PCA, principal component analysis; RT-PCR, quantitative real-time polymerase chain reaction; SELE, E-selectin; SEM, scanning electron microscopy

Received 01.5.13; revised 20.6.13; accepted 15.7.13; Edited by JA Cidlowski; published online 30.8.13
} 
mediate 'oxidative' toxicity of $\mathrm{Hb}$ to endothelial cells. The toxic species identified include primary globin denaturation products and secondary lipoprotein peroxidation products, both of which result from the continuous reactions of $\mathrm{Hb}$ with physiological levels of $\mathrm{H}_{2} \mathrm{O}_{2}$.

Our results suggest that the anti-oxidative function of $\mathrm{Hp}$ against endothelium-directed $\mathrm{Hb}$ toxicity is based primarily on two activities. First, $\mathrm{Hp}$ stabilizes the protein structure of $\mathrm{Hb}$ itself, thus preventing unfolding and aggregation of the protein, and second, $\mathrm{Hp}$ halts heme and/or radical transfer from $\mathrm{Hb}$ to reactive lipoproteins. Importantly, this caging effect of $\mathrm{Hp}$ allows the $\mathrm{Hb} / \mathrm{Hp}$ complex to function as a protective sink for reactive oxygen species within $\mathrm{Hb}$ - and $\mathrm{H}_{2} \mathrm{O}_{2}$ exposed tissues.

\section{Results}

$\mathrm{Hb}$ degradation products are an Hp-attenuated mediator of endothelial damage. We incubated human endothelial cells with human $\mathrm{Hb}\left(\mathrm{Fe}^{2+}, 2 \mathrm{mg} / \mathrm{ml}\right)$ and a low level of the $\mathrm{H}_{2} \mathrm{O}_{2}$-generating enzyme glucose oxidase (GOX; $2.5 \mathrm{mU} / \mathrm{ml}$ ) to simulate the conditions of concurrent extracellular $\mathrm{Hb}$ exposure and oxidative stress (Figure 1). Low activities of GOX in cell culture medium have been found to mimic levels of $\mathrm{H}_{2} \mathrm{O}_{2}$ produced by stimulated neutrophil granulocytes. ${ }^{14}$ Electrical endothelial resistance was measured as a functional surrogate marker of endothelial damage. Combined treatment with human $\mathrm{Hb}$ and GOX resulted in a rapid decrease in endothelial resistance that occurred within hours of the onset of the incubation period. Figure 1a shows representative experiments for human umbilical vein endothelial cells (HUVECs) and human pulmonary artery endothelial cells (HPAECs); comparable results were obtained with human lung microvascular endothelial cells (HLMVECs) and human lymphatic endothelial cells (HLyECs) in preliminary studies (data not shown). This decrease in endothelial electrical resistance was accompanied by the redistribution of the adherens junction protein $\beta$-catenin and ultrastructural evidence of intercellular gap formation in regions with decreased $\beta$-catenin staining (Figure 1b). In contrast, when applied alone, even prolonged incubations with either human $\mathrm{Hb}$ or GOX did not induce any measurable changes in cell function or morphology. The GOX activity used in these studies has been shown to generate steady-state $\mathrm{H}_{2} \mathrm{O}_{2}$ levels in the range of $5-20 \mu \mathrm{M}$ in cell culture, which is in a low supra-physiologic range observed acutely after wounding. ${ }^{12,21,22}$ Gene array analysis confirmed that the low level of $\mathrm{H}_{2} \mathrm{O}_{2}$ generated in this model induced only minimal changes in overall gene expression that were not indicative of oxidative stress or cell damage (Supplementary Figure 1).

The human $\mathrm{Hb}+\mathrm{GOX}$-induced damage in HPAEC (Figure 1c) was completely prevented by the addition of purified human $\mathrm{Hp}(2 \mathrm{mg} / \mathrm{ml})$. Identical protection was also found for other endothelial cell types (HPAEC, HLMVEC, and HLyEC; data not shown).

Our earlier studies suggested that $\mathrm{Hb}$ bound to $\mathrm{Hp}$ in the $\mathrm{Hb}$ / $\mathrm{Hp}$ complex can still react with $\mathrm{H}_{2} \mathrm{O}_{2}$, but the structure of the $\mathrm{Hb} / \mathrm{Hp}$ complex remains protected from oxidative damage and denaturation. ${ }^{23}$ In contrast, in the absence of $\mathrm{Hp}$, free $\mathrm{Hb}$ is extensively oxidized at specific amino-acid sites leading to structural destabilization of the protein with subsequent denaturation, covalent protein cross-linking, and aggregation. $^{24,25,26}$ Therefore, we speculated that the toxicity that occurs in our model in the absence of $\mathrm{Hp}$ may be induced by such $\mathrm{Hb}$ denaturation and aggregation products. To test this hypothesis, we probed our cell culture system with two types of $\mathrm{Hb}$ that are more resistant to oxidative protein degradation by $\mathrm{H}_{2} \mathrm{O}_{2}$. These proteins were (1) $\alpha$ - $\alpha$-cross-linked human $\mathrm{Hb}$ $(\alpha \mathrm{XLHb})$. This $\mathrm{Hb}$ is a tetrameric $\mathrm{Hb}$, which is stabilized by the chemical cross-linker bis(3,5-dibromosalicyl)fumarate (DBBF), and (2) bovine $\mathrm{Hb}(\mathrm{bvHb})$, which is a dissociable tetramer with an enhanced conformational stability because of its specific amino-acid sequence. Aggregation that could occur upon unfolding of the different $\mathrm{Hbs}$ as well as of the $\mathrm{Hb} / \mathrm{Hp}$ complex during $\mathrm{H}_{2} \mathrm{O}_{2}$ reactions can be monitored by spectrophotometry. As shown in Figure $2 \mathrm{a}$, aggregate formation can be observed with native human $\mathrm{Hb}$ but not with $\alpha \mathrm{XLHb}, \mathrm{bvHb}$, or the $\mathrm{Hb} / \mathrm{Hp}$ complex. In strong correlation with the absent aggregate formation, the oxidation of the structurally stabilized $\mathrm{Hbs}$ was not associated with endothelial damage (Figure 2b). The generation of $\mathrm{Hb}$ denaturation products with the unstable human $\mathrm{Hb}$ could also be observed in cell culture by scanning electron microscopy (SEM; Figure 2c). We found extensive aggregate endothelial cell interactions with engulfment of the nanometer- to micrometersized particles by HPAECs (Figure 2d). Therefore, we assumed that one mechanism of oxidative $\mathrm{Hb}$ toxicity is directly related to the appearance of these $\mathrm{Hb}$ denaturation/ aggregation products that have the ability to initiate endothelial cell damage (mechanism 1 in Figure 7).

The intrinsic $\mathrm{Hb}$ oxidation pathway generates toxic reaction products that are attenuated by $\mathrm{Hp}$. To conclusively dissect the biological impact of the different $\mathrm{Hb}$ oxidation products, we biochemically characterized the $\mathrm{H}_{2} \mathrm{O}_{2}$ reactions of all evaluated types of $\mathrm{Hb}$ and correlated the generation of different oxidation products with the observed biological responses of endothelial cells. Under identical conditions as in our cell culture experiments (i.e., $37^{\circ} \mathrm{C}$ and complete endothelial cell culture medium), $\mathrm{Hb}$ heme-iron oxidation with production of $\mathrm{HbFe}^{3+}$ and $\mathrm{HbFe}^{4+}$ was similar for human $\mathrm{Hb}, \alpha \mathrm{XLHb}$, bvHb, and the $\mathrm{Hb} / \mathrm{Hp}$ complex (Figure $3 a$ ). Heme release was slightly reduced with bvHb and $\alpha \mathrm{XLHb}$, but only the $\mathrm{Hb} / \mathrm{Hp}$ complex completely prevented heme transfer from ferric $\mathrm{Hb}$ to hemopexin (Hpx; Figures 3b and c). EPR-detectable 5-(diethoxyphosphoryl)-5-methyl-1-pyrroline- $N$-oxide (DEPMPO) radicals were highest with the $\mathrm{Hb} / \mathrm{Hp}$ complex, which is compatible with a radical-stabilizing function of $\mathrm{Hp} .{ }^{11}$ Human $\mathrm{Hb}, \alpha \mathrm{XLHb}$, and $\mathrm{bvHb}$ all led to similar levels of free radical production (Figure 3d).

In this first model, it is likely that the $\mathrm{Hb}$ degradation products, which are unique for the $\mathrm{H}_{2} \mathrm{O}_{2}$ reaction with the human $\mathrm{Hb}$, are the toxic species. Generation of the primary heme-iron oxidation products $\left(\mathrm{Hb}-\mathrm{Fe}^{3+}\right.$ and $\left.\mathrm{Hb}-\mathrm{Fe}^{4+}\right)$, DEPMPO-trappable radicals, and free heme are common among all reactions that occurred in the toxic as well as in the nontoxic conditions. These species could therefore be excluded as the ultimate mediators of toxicity. 
a

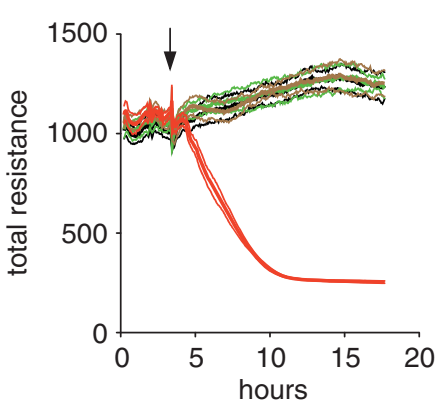

HPAEC

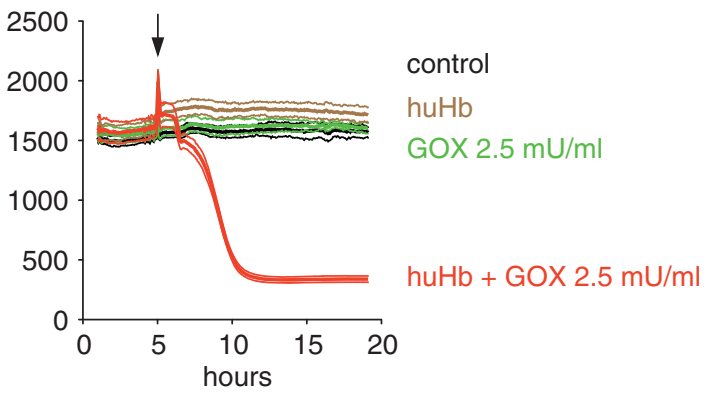

fluorescence + SEM (merge) b
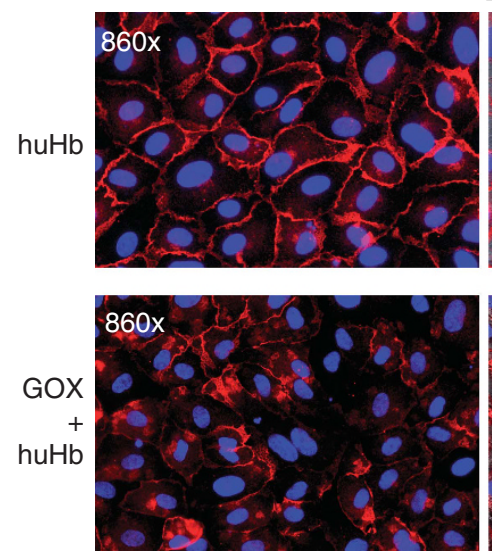

C

control

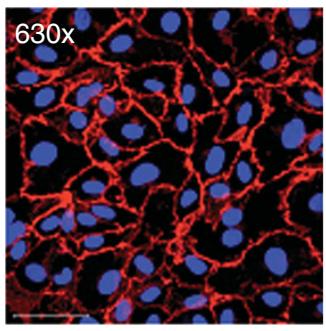

$\beta$-catenin
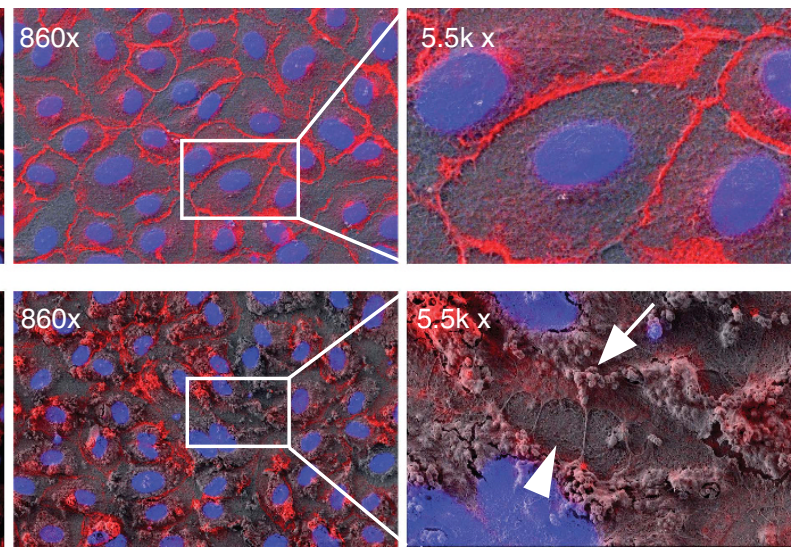

huHb
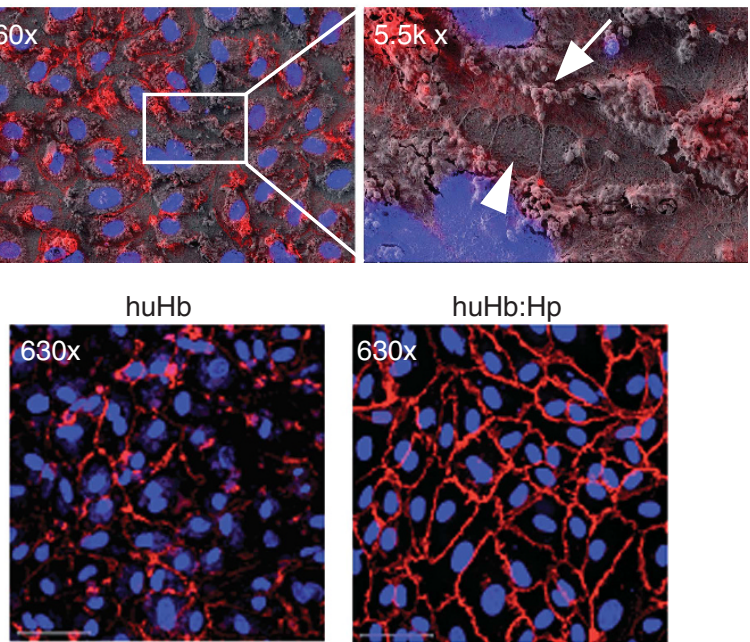

huHb:Hp

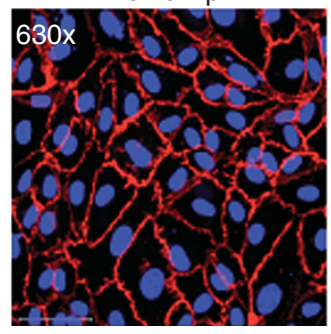

GOX $2.5 \mathrm{mU} / \mathrm{ml}$

Figure $1 \mathrm{Hb}$ oxidation, endothelial damage, and $\mathrm{Hp}$ protection. (a) Endothelial monolayer electrical resistance during treatment with human $\mathrm{Hb}$ (huHb, $2 \mathrm{mg} / \mathrm{ml}$ ), a low/ nontoxic level of GOX $(2.5 \mathrm{mU} / \mathrm{ml})$, or the combination of huHb + GOX. Only the combination of huHb $+\mathrm{GOX}$ resulted in a significant decline of endothelial resistance over time. ECIS traces represent means \pm S.D. of four replicate measurements. (b) The decline of HPAEC monolayer resistance was morphologically associated with a redistribution of the adherens junction protein $\beta$-catenin (red) in fluorescence light microscopy (blue =DAPI-stained nuclei). Imaging of the same specimen region with a correlative SEM revealed intercellular gap formation (arrow head) with intercellular space spanning filopodia in the regions with decreased $\beta$-catenin staining. The arrow indicates a conglomerate of $\mathrm{Hb}$ aggregates. No changes were observed when cells were only treated with $\mathrm{Hb}$ or GOX alone (data not shown). The incubation time in these experiments was $6 \mathrm{~h}$. (c) $\beta$-Catenin (red) redistribution in HPAECs was completely prevented when $\mathrm{Hp}(2 \mathrm{mg} / \mathrm{ml})$ was present during the combined huHb $+\mathrm{GOX}$ treatment in confocal laser scanning microscopy images (original magnification $\times 630$ )

The extrinsic $\mathrm{Hb}$ oxidation pathway generates toxic lipid oxidation products in the absence of $\mathrm{Hp}$. To evaluate the role of $\mathrm{Hb}$ reactions with extrinsic (non- $\mathrm{Hb}$ ) molecules, we supplemented our cell culture model by adding human plasma-derived low-density lipoprotein (LDL) as a potential substrate of $\mathrm{Hb}$ 's peroxidative activity. The addition of $0.5 \mathrm{mg} / \mathrm{ml} \mathrm{LDL}$ to the $\mathrm{Hb}-\mathrm{H}_{2} \mathrm{O}_{2}$ reaction led to a cytotoxic endothelial response with loss of electric monolayer resistance (Figures $4 \mathrm{~b}$ and $\mathrm{c}$ ). This endothelial damage mechanism was independent of $\mathrm{Hb}$ 's intrinsic structural stability and did occur with human $\mathrm{Hb}$, bvHb (Figure 4b), and $\alpha \mathrm{XLHb}$ (Figure $4 \mathrm{c}$ ). No changes in electrical resistance and/or morphology were observed during incubation of endothelial cells with $\mathrm{LDL} \pm \mathrm{GOX}$ in the absence of $\mathrm{Hb}$. The $\mathrm{Hb} / \mathrm{Hp}$ complex attenuated $\mathrm{Hb}$-driven $\mathrm{LDL}$ peroxidation and, accordingly, Hp significantly delayed the endothelial monolayer damage that was associated with $\mathrm{Hb}$-driven LDL oxidation (Figure 4c; mechanism 2 in Figure 7).

Inflammation versus cytotoxicity. Intrinsic and extrinsic oxidative $\mathrm{Hb}$ reaction pathways trigger distinct endothelial damage. Based on the presented experiments, 

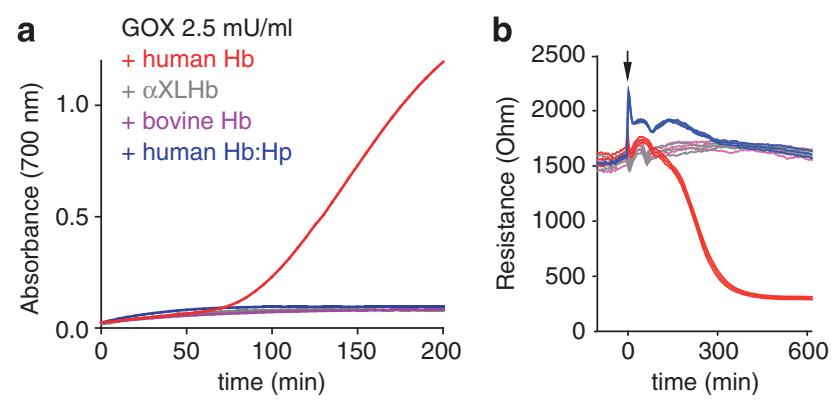

C
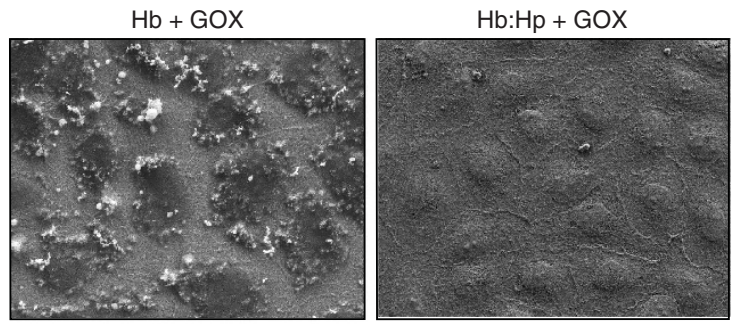

d

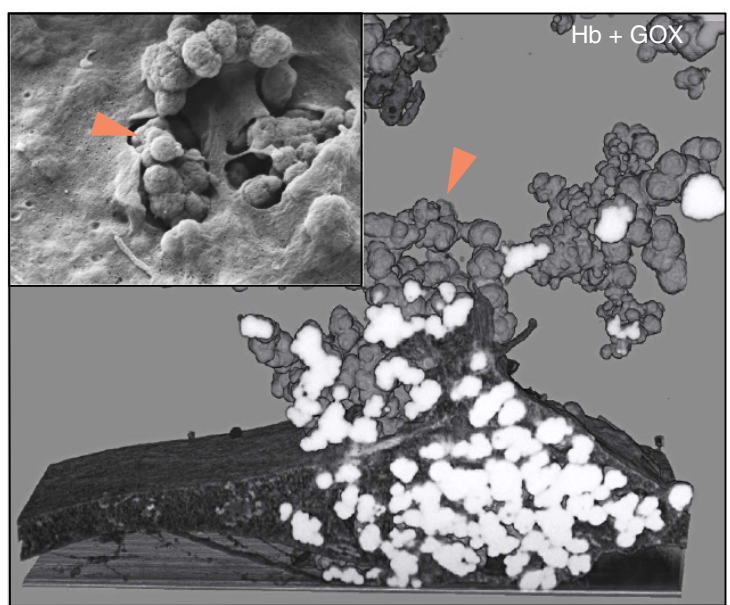

Figure $2 \mathrm{Hb}$ oxidative stability, aggregate formation, and endothelial damage. (a) Aggregate formation during the reaction of $\mathrm{H}_{2} \mathrm{O}_{2}(\mathrm{GOX} 2.5 \mathrm{mU} / \mathrm{ml})$ with the different types of $\mathrm{Hb}(2 \mathrm{mg} / \mathrm{ml})$ was recorded by time-resolved spectrophotometry at $700 \mathrm{~nm}$ under identical conditions as in the ECIS experiment with HPAEC shown in (b). At equal $\mathrm{H}_{2} \mathrm{O}_{2}$ exposure, endothelial barrier function was compromised in the presence of huHb but not in the presence of the structure-stable $\alpha \mathrm{XLHb}$ or bvHb. The addition of $\mathrm{Hp}(2 \mathrm{mg} / \mathrm{ml})$ to the huHb $+\mathrm{GOX}$ reaction (red line) completely prevented aggregate formation and endothelial barrier breakdown (blue line). (c) The aggregates/precipitates can be localized on HPAEC by SEM (images were recorded after $5 \mathrm{~h}$ ). No aggregates can be visualized in the presence of $\mathrm{Hp}$. (d) Internalization of the $\mathrm{Hb}$ aggregates (arrows) by the endothelial cells can be observed on zoom-in cell surface views (insert) and in a 3D reconstruction of serial sections recorded with a FIB-SEM instrument. The white color appearance of the $\mathrm{Hb}$ precipitates on the front section of the $3 \mathrm{D}$ image is indicative of the high density of these particles that allowed automatic recognition and reconstruction by the image processing software (Imaris Software), which clearly show internalized particles as well as particle aggregates on the surface of the cell

two principal oxidative $\mathrm{Hb}$ reaction pathways can be discriminated. An intrinsic oxidation pathway generates $\mathrm{Hb}$ degradation products, whereas an extrinsic oxidation pathway generates secondary lipid oxidation products. Both of them can eventually lead to endothelial damage and both are attenuated by $\mathrm{Hp}$ (Figure 7). Further evidence for the discriminative nature of these two mechanisms could be provided if unique cellular responses could be defined that are specifically triggered by these two reactions. Therefore, we characterized the messenger ribonucleic acid (mRNA) expression profile of HPAECs in response to the two toxic reactions by gene array analysis (Figure 5).

Figure $5 \mathrm{a}$ summarizes the reaction products that are generated during the different toxic and nontoxic incubation conditions and which eventually could stimulate transcriptional responses in endothelial cells. Figure $5 \mathrm{~b}$ shows a principal component analysis (PCA) of the global mRNA transcriptome changes triggered by the different treatments. The PCA shows that the individual experimental samples cluster within three distinct groups. Within the first group (multiple colors) we find the control samples, as well as the samples that were exposed to the previously defined nontoxic $\mathrm{Hb}$ reactions. Specifically, within this group we identified the samples that were only treated with $\mathrm{Hb}\left(\mathrm{Fe}^{2+}\right)$ as well as the samples treated with the structurally stable bvHb $+\mathrm{GOX}$ where redox cycling ( $\mathrm{Fe}^{3+} / \mathrm{Fe}^{4+}$ formation) as well as heme release and radical production (but not globin degradation or LDL oxidation) do occur. These data confirm that in this model radical generation, ferric and ferryl $\mathrm{Hb}$ formation and heme release are not the immediate inducers of the adverse endothelial response. In contrast, the transcriptome profile of the samples treated with the unstable human $\mathrm{Hb}+\mathrm{GOX}$ (green) and samples exposed to bvHb + LDL + GOX (brown) clearly separated from each other and from all other conditions.

To extract meaningful gene signatures that may better define the apparently dichotomous adverse cellular responses, we have selected all genes that were differently expressed in any of the five tested conditions. The level of selection stringency was set at greater than twofold upregulation compared with control cells at FDR 0.05 (ANOVA). The 2046 genes that met these inclusion criteria served as an input data set for the hierarchical two-way clustering analysis shown in Figure 5c. As expected from the PCA, the samples treated with 'nontoxic' conditions do not separate from each other and it is not reasonable to extract characteristic gene clusters or expression patterns for any of these treatments, underpinning the minimal impact of the 'common' $\mathrm{Hb}$ reaction products on the endothelium. However, the samples treated with bvHb $+\mathrm{LDL}+\mathrm{GOX}$ and those treated with human $\mathrm{Hb}+\mathrm{GOX}$ clustered in two distinct groups were clearly discriminated from each other by non-overlapping gene signatures (see also Supplementary Excel Table for more detailed data).

A functional analysis of the exposure-specific gene clusters was performed with a comparative Metacore (Thomson Reuters, New York, NY, USA) network analysis. The top 10 significantly enriched functional networks for each condition are shown in Figure 5d. The response of cells treated with $\mathrm{bvHb}+\mathrm{LDL}+\mathrm{GOX}$ (gene cluster A) is characterized by upregulation of heat shock proteins (e.g., heat shock protein 70) and activating transcription factor 3 (ATF3), which is a known stress-inducible transcription factor. ${ }^{27}$ In contrast, the human $\mathrm{Hb}$ aggregates evoke a paramount inflammatory response with the adhesion molecule E-Selectin (SELE) as the most upregulated signature gene (gene cluster B; see also Supplementary Excel Table and Supplementary Figure 3 for more detailed data). 
a
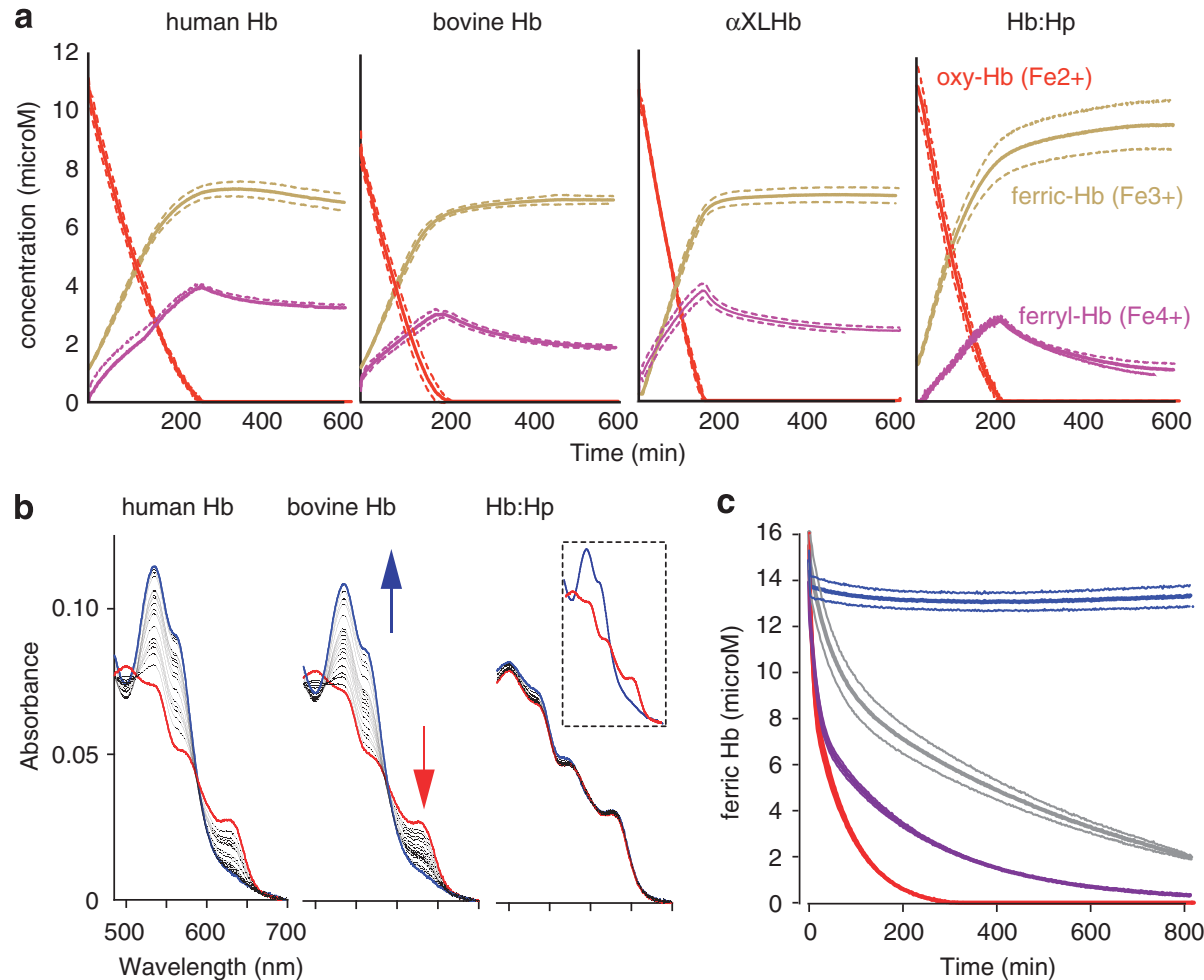

$\mathrm{Hb}: \mathrm{Hp}$

C
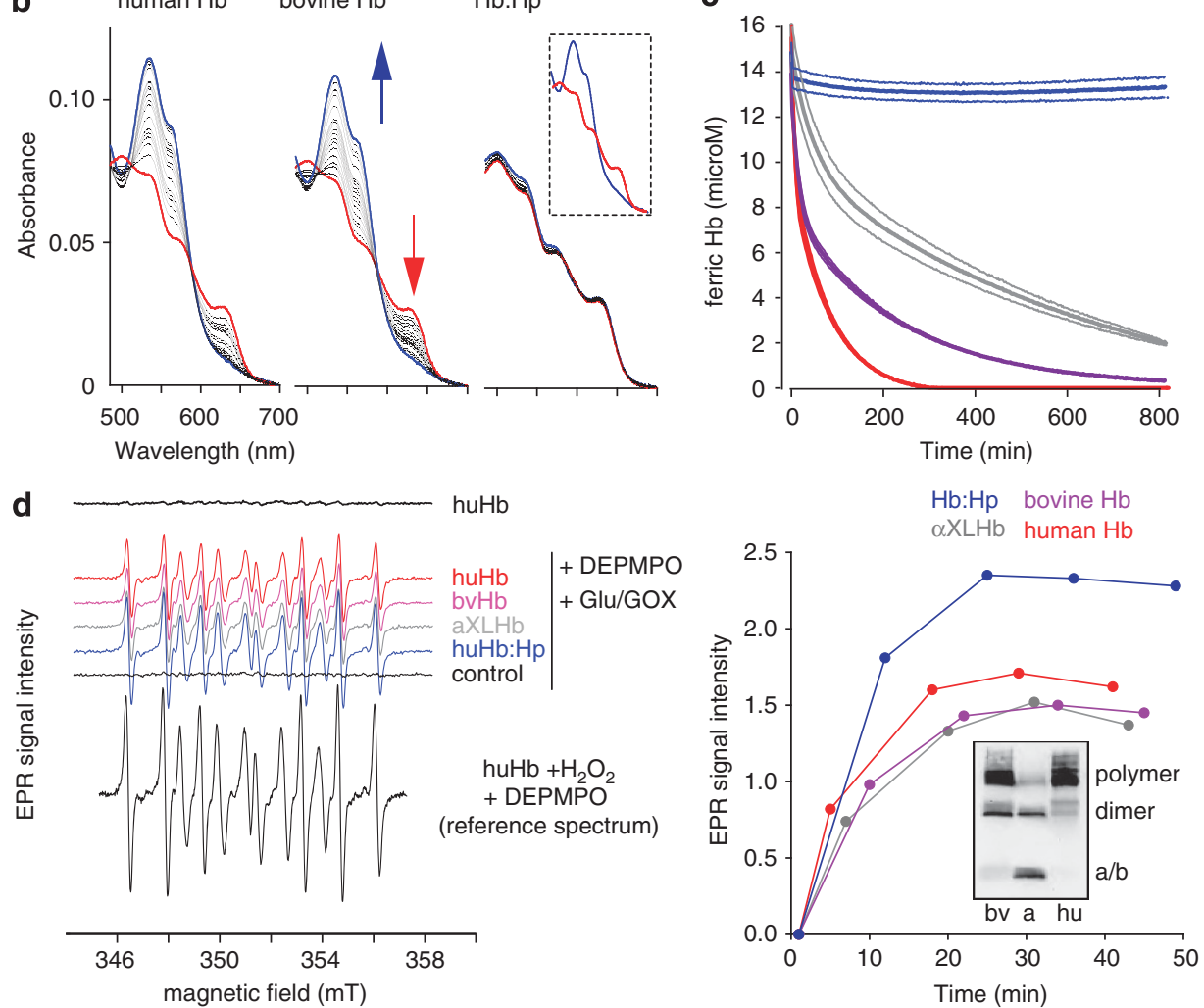

Figure 3 Biochemical characterization of the $\mathrm{H}_{2} \mathrm{O}_{2}$ reactions with human $\mathrm{Hb}$, bvHb, $\alpha-\alpha$-cross-linked $\mathrm{Hb}$, and the $\mathrm{Hb} / \mathrm{Hp}$ complex. (a) Time-resolved analysis of the reactions of the different types of $\mathrm{Hb}$ in complete endothelial cell culture medium at $37^{\circ} \mathrm{C}$. Spectra were recorded at 2-min intervals and deconvoluted to calculate the concentrations of the individual $\mathrm{Hb}$ oxidation states. (b) Heme release and transfer to $\mathrm{Hpx}$ from ferric $\mathrm{Hb}$. Serial spectra were recorded from a mixture of ferric $\mathrm{Hb}(12.5 \mu \mathrm{M})$ with a 10-fold molar excess of $\mathrm{Hpx}$. The first spectrum is red (ferric $\mathrm{Hb}$ ) and the last recorded spectrum is blue (heme-Hpx). The insert shows the reference spectra of ferric $\mathrm{Hb}$ (red) and heme-Hpx (blue), respectively. (c) Decay of ferric $\mathrm{Hb}$ over time. (d) Radical generation during $\mathrm{Hb}_{-} \mathrm{H}_{2} \mathrm{O}_{2}$ reactions was explored with spin-trapping EPR under the same conditions used for endothelial cell culture (cell culture medium, $\mathrm{Hb}(2 \mathrm{mg} / \mathrm{ml})$, and GOX $(2.5 \mathrm{mU} / \mathrm{ml})$ ) in the presence of $50 \mathrm{mM} \mathrm{DEPMPO}$. EPR spectra (left panel) of the different experimental samples were recorded sequentially over time, and the integrated spectral values are plotted in the right panel. The insert shows an anti-DMPO Western blot of $\mathrm{Hbs}$ reacted with $\mathrm{H} 2 \mathrm{O} 2$ in the presence of DMPO. The signals indicate generation of protein based radicals

The apparent dichotomy of the cellular responses to the $\mathrm{Hb}$ aggregates and the oxidized LDL, respectively, can also be illustrated by a morphological analysis of adherence junction ( $\beta$-catenin) and cytoskeleton (actin) morphology (Supplementary Figure 2).

The shielded pseudoperoxidase activity of $\mathrm{Hb}$ within the $\mathrm{Hb} / \mathrm{Hp}$ complex can protect endothelial cells against peroxidative damage. Formation of the $\mathrm{Hb} / \mathrm{Hp}$ complex does not change the pseudoperoxidase $\left(\mathrm{H}_{2} \mathrm{O}_{2}\right.$-consuming $)$ activity of $\mathrm{Hb}$. Therefore, as an ultimate effect, $\mathrm{Hp}$ protection could imply that this pseudoperoxidase activity could represent a novel antioxidant function of the complex. ${ }^{23,26,28}$ To test this hypothesis, we adjusted our cell culture system to mimic conditions of toxic $\mathrm{H}_{2} \mathrm{O}_{2}$ exposure (Figure 6). The amount of $\mathrm{H}_{2} \mathrm{O}_{2}$ generated in situ by $20 \mathrm{mU} / \mathrm{ml} \mathrm{GOX}$ (high GOX) is estimated to produce $\mathrm{H}_{2} \mathrm{O}_{2}$ steady-state levels in high supra-physiologic range $(50-100 \mu \mathrm{M})$ and induced endothelial cell damage. ${ }^{21}$ Specifically, redistribution/ disappearance of the adherens junction protein $\beta$-catenin and a decrease in transendothelial resistance could be observed within hours (Figures 6a and c). In accordance with 
a

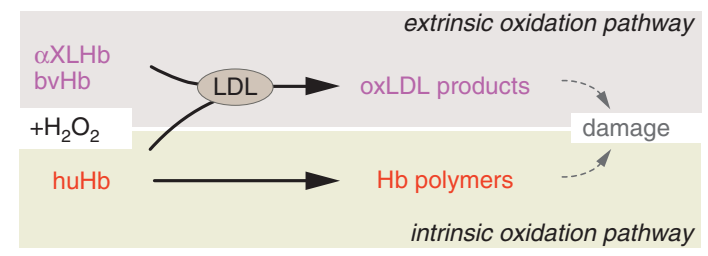

b

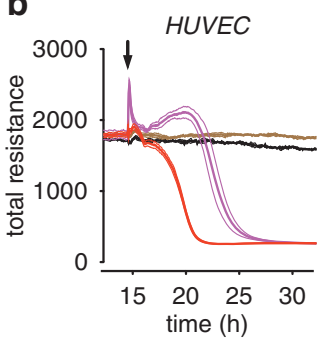

C
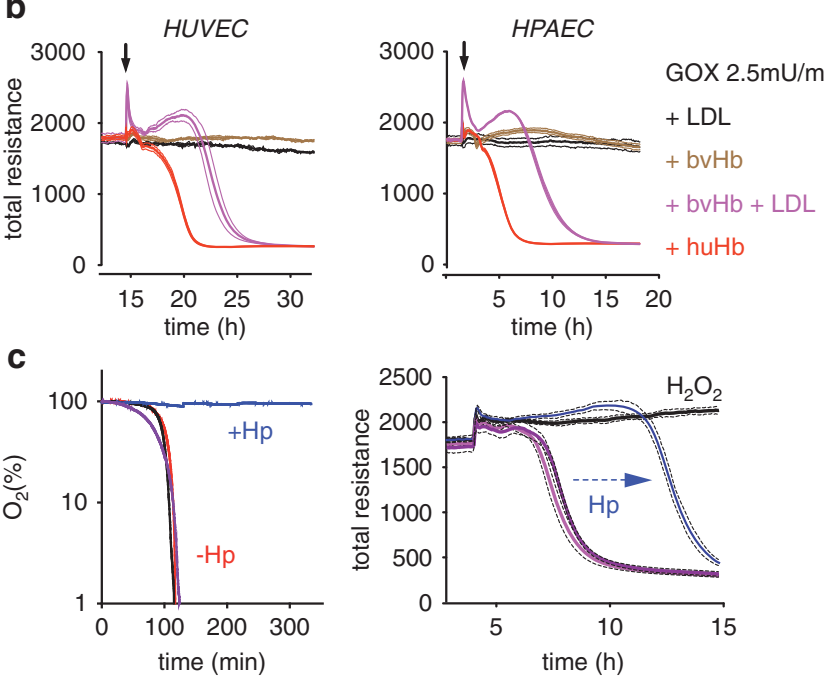

Figure 4 Intrinsic and extrinsic reaction pathways of $\mathrm{Hb}$ peroxidative endothelial damage. (a) The 'intrinsic' oxidation pathway (red) involves globin oxidation with the subsequent formation of $\mathrm{Hb}$ aggregates that induce direct endothelial damage. The proposed 'extrinsic' pathway (violet) involves oxidative transformation of bystander molecules (i.e., LDL) into toxic reaction products. (b) HUVECs and HPAECs were incubated with either LDL $(0.5 \mathrm{mg} / \mathrm{ml})+\mathrm{GOX} 2.5 \mathrm{mU} / \mathrm{ml}$, bvHb $(2 \mathrm{mg} / \mathrm{ml})+\mathrm{GOX}$, or $\mathrm{LDL}+\mathrm{bvHb}+\mathrm{GOX}$ to explore the extrinsic pathway of peroxidative toxicity. To compare the extrinsic pathway with the intrinsic pathway, some cells were treated with huHb $(2 \mathrm{mg} / \mathrm{ml})+\mathrm{GOX}$. Transendothelial resistance was measured with an ECIS instrument. (c) $\mathrm{Hb}$-mediated LDL oxidation and protection by $\mathrm{Hp}$. Left panel: $\mathrm{O}_{2}$ consumption was measured with an $\mathrm{O}_{2}$ sensitive micro-electrode in stirred reaction mixtures of $\mathrm{LDL}$ with huHb-Fe${ }^{3+}$ (red), $\alpha \mathrm{XLHb}-\mathrm{Fe}^{3+}$ (dark violet), bvHb$\mathrm{Fe}^{3+}$ (black), or huHb-Fe ${ }^{3+} / \mathrm{Hp}$ complex (blue). Right panel: the $\mathrm{Hb} / \mathrm{Hp}$ complex (blue line) delayed the breakdown of endothelial electrical resistance compared with when $\alpha \mathrm{XLHb}$ (dark violet) or bvHb (violet) were used in the reaction mixture with $\mathrm{LDL}+\mathrm{GOX}$. The control treatment (black line) was $\mathrm{LDL}+\mathrm{GOX}$ in the absence of any $\mathrm{Hb}(\mathrm{LDL} 0.5 \mathrm{mg} / \mathrm{ml}$ and $\mathrm{Hbs} 0.1 \mathrm{mg} / \mathrm{ml})$. All ECIS traces represent mean \pm S.D. values of four replicate measurements

our previous experiments, endothelial damage appeared to even be amplified when free huHb was added to the $\mathrm{H}_{2} \mathrm{O}_{2}$ generating system and, consequently, toxic denaturation products were formed (Figure 6c). However, the gene expression analysis shown in Figure $6 \mathrm{~b}$ suggested that $\mathrm{Hb}$ switches the cellular mechanism of $\mathrm{H}_{2} \mathrm{O}_{2}$-mediated damage from oxidative stress to inflammation. In agreement with the $\mathrm{H}_{2} \mathrm{O}_{2}$-consuming activity of $\mathrm{Hb}$, the $\mathrm{H}_{2} \mathrm{O}_{2}$-associated gene cluster (gene cluster A) was normalized when extracellular $\mathrm{Hb}$ was present in the treatment. The top upregulated gene within this $\mathrm{H}_{2} \mathrm{O}_{2}$ signature cluster is the stress-signaling transcription factor ATF3 (Supplementary Excel file). ${ }^{27}$ In contrast, the new gene cluster that appeared when $\mathrm{Hb}$ was added to the oxidative system represents inflammation (gene cluster B). The $\mathrm{Hb}$-mediated switch from oxidative stress to inflammation could be confirmed by quantitative real-time polymerase chain reaction (RT-PCR) as a clear switch of high ATF-3 $\rightarrow$ high SELE gene expression (Figure 6d).

Supplementary Figure 3 illustrates the validation of our array gene expression data with TaqMan real-time PCR for 15 genes that represent the oxidative stress (a) and inflammatory (b) gene clusters shown in Figures 6b. For all genes, we found congruent expression patterns between gene array and PCR analysis, with a strong overall correlation between the two methods (Pearson $r^{2}=0.85 ; P<0.0001$ ).

The shielded $\mathrm{Hb} / \mathrm{Hp}$ complex prevented both pathways of endothelial damage and attenuated all associated gene expression changes.

\section{Discussion}

In a standardized cell culture model of concurrent $\mathrm{Hb}$ exposure and oxidative stress, we defined $\mathrm{Hp}$-attenuated mechanisms by which $\mathrm{Hb}$ oxidation could damage the endothelium. Two primary mechanisms could be defined (Figure 7). The first mechanism involves $\mathrm{Hb}$ denaturation products that trigger a strong inflammatory response, whereas the second mechanism involves a cytotoxic reaction induced by oxidatively transformed bystander molecules (i.e., LDL). $\mathrm{Hp}$ stabilizes the $\mathrm{Hb}$ structure (preventing mechanism 1) and shields the environment from $\mathrm{Hb}$-catalyzed oxidation (preventing mechanism 2). These unique protective functions of $\mathrm{Hp}$ indicate an unrecognized biological role of the $\mathrm{Hb} / \mathrm{Hp}$ complex. Within the complex, the pseudoperoxidase activity of $\mathrm{Hb}$ is switched from a destructive to a protective reaction, which may ultimately help to preserve cell integrity during peroxidative stress.

Our in vitro model is conceptually based on a correlative analysis of (1) diverse cellular responses upon in situ oxidative reactions of different types of $\mathrm{Hb}$ and (2) common and divergent structure and reaction properties of these types of $\mathrm{Hb}$ in addition to the $\mathrm{Hb} / \mathrm{Hp}$ complex.

When endothelial cells were exposed to human $\mathrm{Hb}$ in the presence of a nontoxic concentration of GOX, we observed a decrease in transendothelial resistance, a loss of adherens junction organization, and subsequently, a robust inflammatory response. This response was observed in experiments with several endothelial cell types and was completely prevented by the presence of $\mathrm{Hp}$. In contrast to the experiments with human $\mathrm{Hb}$, inflammatory responses, and cell damage were not observed when endothelial cells were exposed to the same peroxidative conditions in the presence of structure-stable Hbs. These results lead to the following questions: (1) What are the differences between the 'toxic' and 'nontoxic' types of $\mathrm{Hb}$ that could explain such a divergent biologic response? (2) Could this observation explain a mechanism whereby $\mathrm{Hp}$ could act as a protective $\mathrm{Hb}$-binding protein?

The types of $\mathrm{Hb}$ in this study are very similar. Human $\mathrm{Hb}$ and $\alpha \mathrm{XLHb}$ have the exact same peptide sequence and comparable quaternary structures and differ only in a defined chemical cross-linker that provides enhanced structural stability to $\alpha \mathrm{XLHb} .^{10} \mathrm{BvHb}$ is a dissociable tetramer with enhanced protein stability to pro-oxidants because of differences in the amino-acid sequence that have accumulated 
a

\begin{tabular}{|c|c|c|c|c|}
\hline \multirow[b]{2}{*}{$\begin{array}{c}\text { hemoglobin } \\
\text { (bvHb }+ \text { huHb) }\end{array}$} & & glucose oxidase (GOX) & & \\
\hline & control & bovine $\mathrm{Hb}$ human $\mathrm{Hb}$ & $\begin{array}{l}\text { bovine } \mathrm{Hb} \\
+\mathrm{LDL}\end{array}$ & treatments \\
\hline $\mathrm{Hb}$ & $\mathrm{H}_{2} \mathrm{O}_{2}$ & \multirow{2}{*}{\multicolumn{2}{|c|}{$\begin{array}{l}\mathrm{Hb}(\mathrm{Fe} 3+) \\
\mathrm{Hb}(\mathrm{Fe} 4+) \\
\text { globin oxidation } \\
\text { protein radicals } \\
\text { heme release }\end{array}$}} & \multirow{4}{*}{$\begin{array}{l}\text { in situ reaction products } \\
\text { non toxic } \\
\text { toxic }\end{array}$} \\
\hline & & & & \\
\hline & & \multirow[t]{2}{*}{$\mathrm{Hb}$ aggregates } & & \\
\hline & & & oxLDL & \\
\hline
\end{tabular}

b

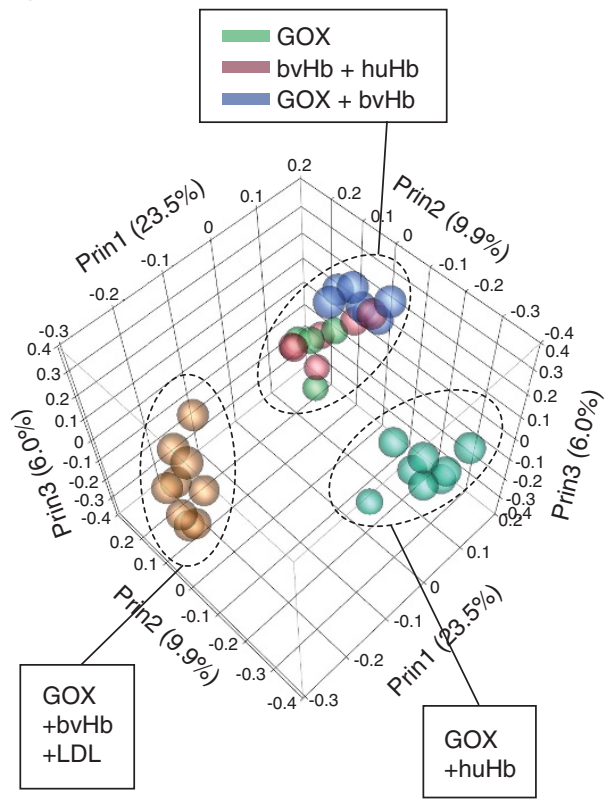

c $\square$ GOX

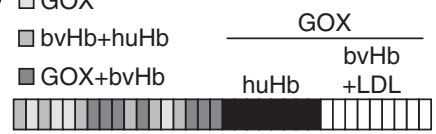

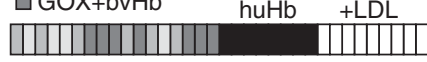

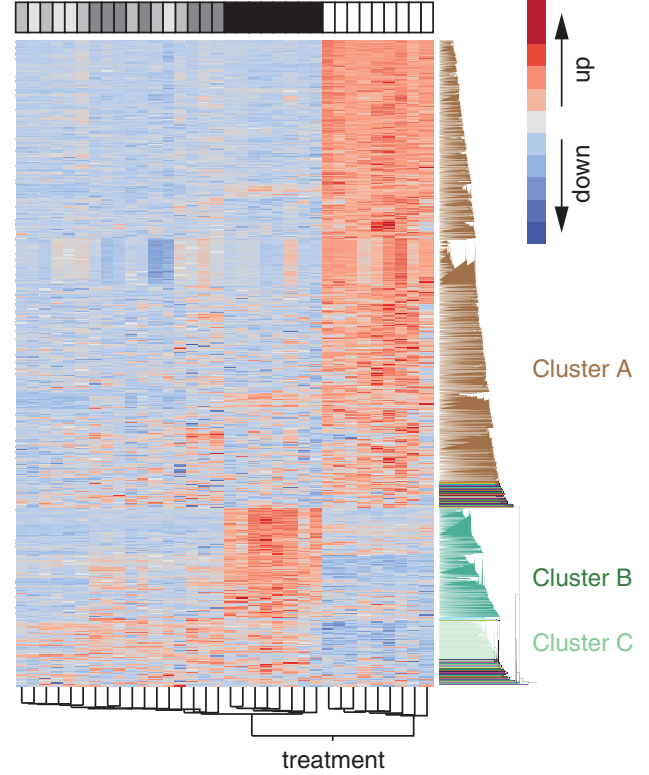

- $\log 10$ (p-Value)

d

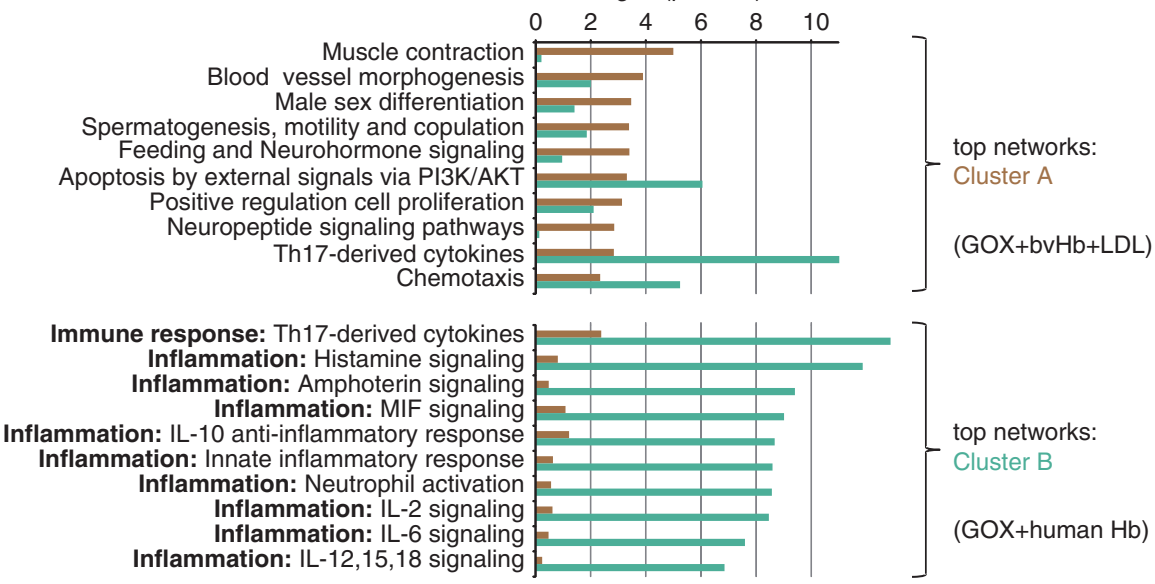

Figure 5 Gene expression analysis of endothelial cells exposed to $\mathrm{Hb}$-catalyzed oxidative reactions. (a) Reaction components (= endothelial cell treatments) and the proposed in situ reaction intermediates and end products. (b) HPAECs were exposed to the indicated components for $8 \mathrm{~h}$. The global mRNA expression pattern was analyzed by Agilent gene expression arrays. In the PCA, the global expression profile of each sample is represented as a ball that is color coded for its treatment condition. (c) Hierarchical clustering analysis of all genes that were significantly changed from baseline expression by any treatment condition. Each column represents the color-coded gene expression pattern of a single sample. Treatment conditions are indicated at the top of the graph. The treatment discriminative gene clusters that were used for functional network analysis are indicated at the right border of the graph. (d) The treatment discriminative gene clusters A (LDL peroxidation) and B ( $\mathrm{Hb}$ degradation) were analyzed with Metacore software for the enrichment of functional gene networks. The 10 most significantly enriched networks are indicated 
a

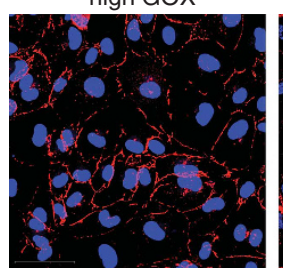

+ hu Hb

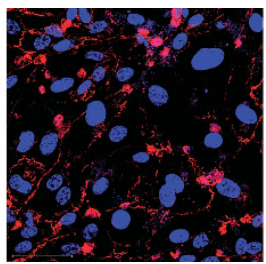

+ hu Hb:Hp

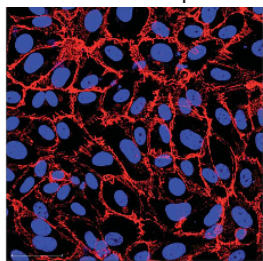

b

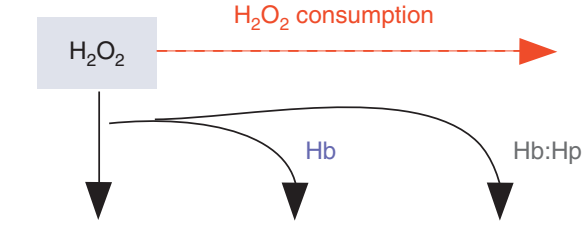

toxicity

protection

high GOX $\quad$ human $\mathrm{Hb}$ + human $\mathrm{HbHp}$

metacore

networks

- stress signalling

(ATF-3,C-Jun/c-Fos)

- apoptosis

(endoplasmatic

reticulum, stress)

- inflammation

- chemotaxis

- apoptosis
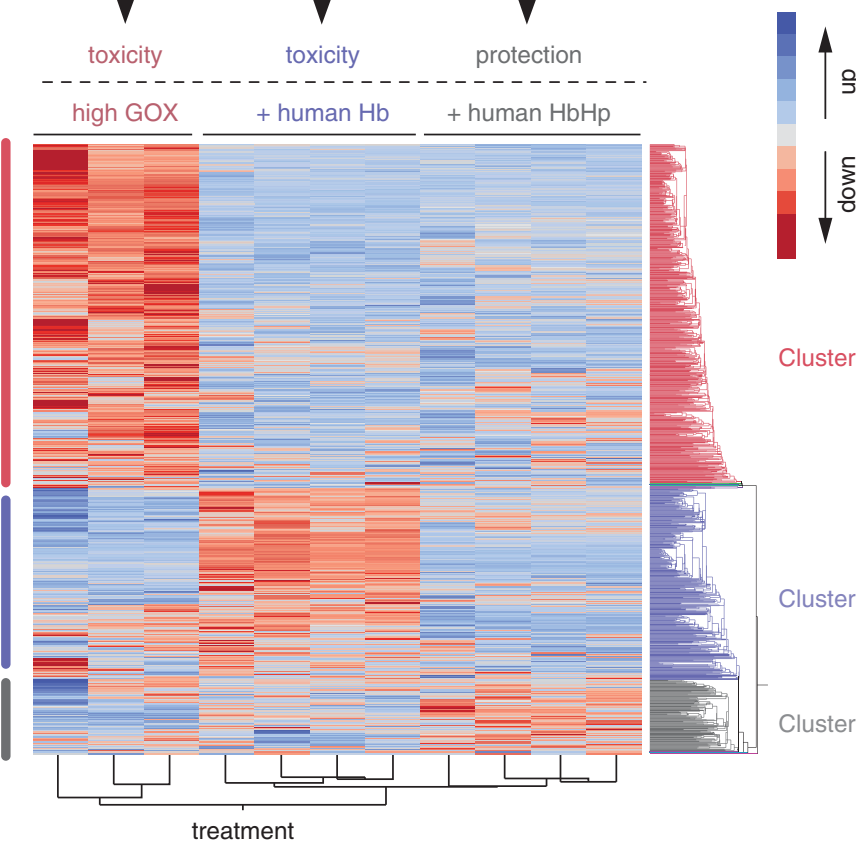

Cluster A

Cluster B

Cluster C
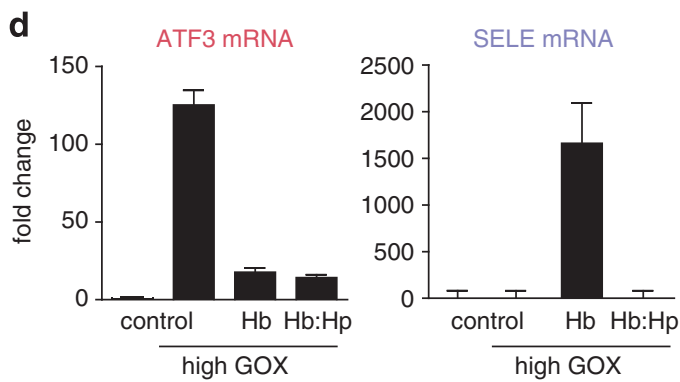

Figure 6 The $\mathrm{Hb} / \mathrm{Hp}$ complex is a protective sink for cytotoxic extracellular $\mathrm{H}_{2} \mathrm{O}_{2}$. High-dose $\mathrm{H}_{2} \mathrm{O}_{2}$-mediated endothelial cell toxicity was mimicked by treating confluent HUVEC endothelial monolayers with $20 \mathrm{mU} / \mathrm{ml} \mathrm{GOX} \mathrm{(high} \mathrm{GOX).} \mathrm{(a)} \beta$-Catenin (red) immunofluorescence of endothelial cells incubated with high GOX, high GOX + huHb, or high $\mathrm{GOX}+\mathrm{Hb} / \mathrm{Hp}$ (blue $=\mathrm{DAPI}$-stained nuclei, original magnification $\times 630$ ). (b) Global gene expression changes observed after $8 \mathrm{~h}$ with the treatments indicated on the top of the graph. The heat-map shows the result of a hierarchical clustering of the most significantly upregulated (red) and downregulated (blue) genes (compared with untreated controls). While there appeared to be almost no significant gene expression changes after high $\mathrm{GOX}+\mathrm{Hb} / \mathrm{Hp}$ treatment, distinct and mutually exclusive clusters of highly regulated genes appeared after treatment with either high GOX alone ( $\rightarrow$ oxidative stress) or high GOX + huHb $(\rightarrow$ inflammation). (c) The breakdown of electrical resistance observed during high GOX treatment (red line) was exaggerated when huHb $(2 \mathrm{mg} / \mathrm{ml}$ ) was added to the system (blue line) and completely halted by the addition of $\mathrm{Hb} / \mathrm{Hp}(2 \mathrm{mg} / \mathrm{ml}$ ) (grey line). (d) RT-PCR confirmation of the representative signature genes of the oxidative stress response (ATF3), which was induced by high GOX alone, and inflammation (SELE), which was only induced by high $\mathrm{GOX}+\mathrm{Hb}$. Hp attenuates both responses to control levels (date are presented as mean \pm S.D. of three independent experiments)

during evolution. Our biochemical characterization confirmed that all three types of $\mathrm{Hb}$ are heme oxidized at comparable rates by $\mathrm{H}_{2} \mathrm{O}_{2}$, thus excluding the ferric $\left(\mathrm{Fe}^{3+}\right)$ and ferryl
$\left(\mathrm{Fe}^{4+}\right)$ forms of $\mathrm{Hb}$ as the immediate cytotoxic species. Also, DEPMPO-trappable radicals were generated at comparable rates and are therefore unlikely to be a direct mediator of 
> mechanism 1: intrinsic oxidation pathway

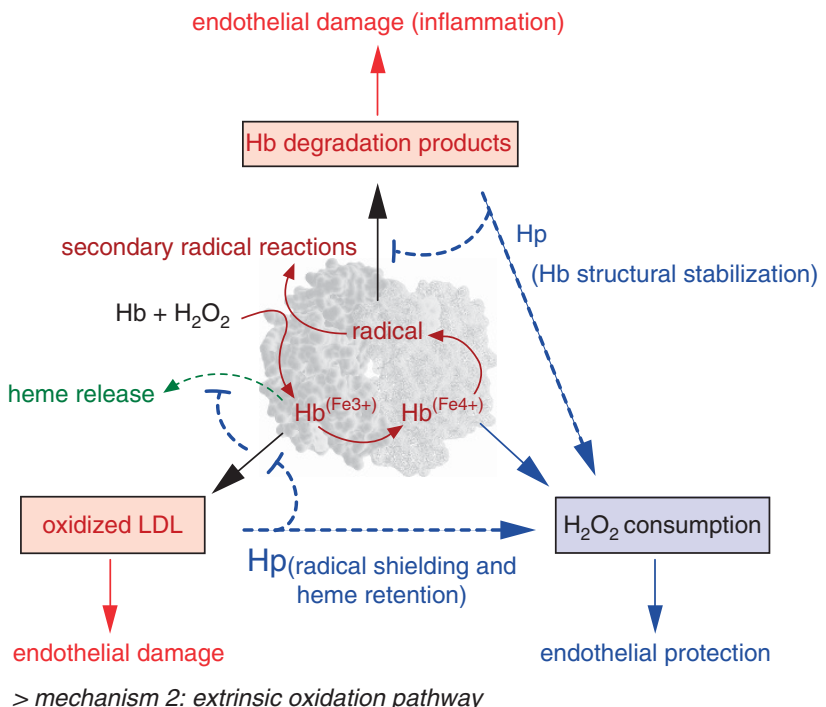

Figure 7 Schematic summary of $\mathrm{Hb}$-catalyzed oxidative endothelial damage and protection by $\mathrm{Hp}$. Graphical illustration of the principal $\mathrm{Hb}$ toxicity and $\mathrm{Hp}$ protection pathways described in this study. We propose that $\mathrm{Hp}$ protects against peroxidative $\mathrm{Hb}$ toxicity by stabilizing the $\mathrm{Hb}$ structure (mechanism 1 ) and by shielding extrinsic molecules against $\mathrm{Hb} /$ heme-mediated peroxidative damage (mechanism 2)

toxicity. We could also disqualify dissociated free heme as the ultimate mediator of cellular damage in this system as it is released from all types of $\mathrm{Hb}$ in the absence of $\mathrm{Hp}$. Presumably, free heme did not exceed the threshold for toxicity in our model. In addition, the endothelial cells were likely protected from heme-mediated cytotoxicity by the presence of plasma proteins in the cell culture medium as well as by a strong baseline heme oxygenase 1 (HO-1) expression that was further enhanced during oxidative $\mathrm{Hb}$ stress. Rather, the role of free heme in our model concerns its ability to enhance oxidative modification of bystander molecules (if present). ${ }^{1,29}$ In a previously published study, we also demonstrated that similar patterns and quantities of primary globin amino-acid oxidation end-products (i.e., formation of cysteic acid at position $\beta$ Cys93) occurred during oxidation of native human and $\alpha \mathrm{XLHb}{ }^{30}$

Collectively, we can exclude the primary heme-oxidized $\mathrm{Hb}$ species (ferric $\mathrm{Hb}^{3+}$ or ferryl $\mathrm{Hb}^{4+}$ ), free heme, $\mathrm{Hb}$ oxidationderived free radicals, and secondary globin amino oxidation products as being the immediate pro-inflammatory and cytotoxic compounds that emerge during $\mathrm{Hb}$ peroxidation.

$\mathrm{Hb}$ is prone to complex oxidation-driven structural modifications, such as loss of $\alpha$-helical structure, covalent globin cross-linking, polymerization, and aggregation. ${ }^{24,25}$ These $\mathrm{Hb}$ polymers/aggregates were the only reaction products that we found to occur with the toxic native human $\mathrm{Hb}$ but not with the two structure-stable Hbs. Endothelial cells extensively interacted with and internalized these degradation products before intercellular gaps, inflammation, and overt cellular damage could be observed. Therefore, as all the other considered reaction intermediates were the same among the three types of $\mathrm{Hb}$, it is likely that these $\mathrm{Hb}$ degradation products triggered the adverse endothelial response. A similar process may also explain the toxicity of $\mathrm{Hb}$ that was oxidatively damaged by the bolus addition of $\mathrm{H}_{2} \mathrm{O}_{2}$ as reported by the Soares group. ${ }^{31}$ In our earlier work, we demonstrated biochemical evidence that $\mathrm{Hp}$ can stabilize the protein structure of $\mathrm{Hb}$ and that this stabilization is essential for the effective recognition of the complex by the macrophage $\mathrm{Hb}$ scavenger receptor CD163. ${ }^{23}$ The model presented in this paper allows us to now, for the first time, relate this $\mathrm{Hb}$-stabilizing activity of $\mathrm{Hp}$ to a strong anti-oxidative protective function within a biological system.

In an extended model that contained extrinsic reactive molecules that could be modified by Hb's peroxidative reactivity, we could confirm that $\mathrm{Hb}$-catalyzed oxidative reactions also generate toxic non-globin products. In this model, the external 'mediator molecule' (LDL) bears the primary impact of the free radical reactivity and is thereby transformed into a toxic compound (i.e., oxLDL). This mechanism of $\mathrm{Hb}$ toxicity is independent of globin stability and is in agreement with numerous earlier studies that explored the lipid-peroxidative properties of free heme and $\mathrm{Hb}$, particularly in the context of atherosclerosis. ${ }^{29,32,33}$ The discriminating gene expression responses triggered by the $\mathrm{Hb}$ degradation and LDL peroxidation products, respectively, suggest that not only the extracellular reactions and toxic species but also the cellular signaling pathways clearly differ between these two principal mechanisms of $\mathrm{Hb}$ toxicity.

$\mathrm{Hp}$ was also capable of blocking Hb-driven LDL oxidation and thereby being protective against this second ('extrinsic') mechanism of $\mathrm{Hb}$-driven endothelial damage. Therefore, the cumulative protective activity of $\mathrm{Hp}$ is related to Hp's ability to stabilize the globin structure and to 'shield' transition of oxidation equivalents from $\mathrm{Hb}$ to other molecules. ${ }^{11,33}$

In the absence of strong protective mechanisms, such as $\mathrm{Hp}$, oxidative side reactions of extracellular $\mathrm{Hb}$ could ultimately link tissue destruction, bleeding, local hemolysis, and oxidative stress to accelerated inflammation and tissue damage. Our studies provide now the first experimental evidence that $\mathrm{Hp}$ can act as a molecular switch, which alters the peroxidative reaction of $\mathrm{Hb}$ away from pro-inflammatory and cytotoxic toward a protective function.

\section{Materials and Methods}

Endothelial cell culture models. All primary human endothelial cells and the respective cell culture media were from Lonza (Basel, Switzerland). Cells were cultured for a maximum of six passages. The following types of $\mathrm{Hb}$ were used throughout the studies: (1) stroma-free human $\mathrm{Hb}(\mathrm{HbAO}$, huHb), which was catalase depleted by DAEA chromatography. (2) Catalase-free ultrapure bvHb. (3) $\mathrm{DBBF} \alpha \mathrm{XLHb}$, both of which were provided by Dr. Abdu Alayash, FDA. $\mathrm{Hb} / \mathrm{H}_{2} \mathrm{O}_{2}$ experiments were performed with either $2.5 \mathrm{mU} / \mathrm{ml}$ (low GOX activity) or $20 \mathrm{mU} / \mathrm{ml}$ GOX (high GOX activity; from Sigma Chemical Co., St. Louis, MO, USA) as indicated. $\mathrm{Hb}$ was used at $2 \mathrm{mg} / \mathrm{ml}$ (ferrous $\mathrm{Hb}$ ) and glucose was used at $4 \mathrm{~g} / \mathrm{l}$. All experiments were performed in complete culture medium (i.e., containing $2 \%$ fetal calf serum and without phenol red). Electrical resistance of the endothelial cell monolayers was measured in real time with an electric cell-substrate impedance sensing (ECIS) Z Theta instrument (ibidi GmbH, Planegg/Martinsried, Germany) that used eight-well disposable electrode arrays $(8 \mathrm{~W} 10+)$. ECIS software version 1.2.52 was used to operate the instrument and for the subsequent data modeling and analysis.

Analysis of $\mathrm{Hb}$ oxidation and radical production during GOX reactions. Spectral analysis of $\mathrm{Hb}$ oxidation by GOX-derived $\mathrm{H}_{2} \mathrm{O}_{2}$ was performed with a Cary 60 UV-VIS Spectrophotometer (Agilent Technologies, Basel, Switzerland). The reactions were monitored in complete endothelial cell 
culture medium under conditions identical to those of the cell culture itself $\left(37^{\circ} \mathrm{C}\right)$. Full spectra were recorded every $3 \mathrm{~min}$ and deconvoluted to calculate the concentrations of the different reaction species. ${ }^{34}$ For the evaluation of aggregate formation, the reactions were continuously measured at $700 \mathrm{~nm}$. For electron paramagnetic resonance (EPR) spin-trapping experiments, the same reactions were performed in the presence of the spin trap DEPMPO $(10 \mathrm{mM})$. During the reaction, samples were measured sequentially in a Bruker ElexSys E500 @ 9.6 GHz X-band cw spectrometer (Bruker BioSpin AG, Faellanden, Switzerand).

Hb-Hpx heme transfer. MetHb $\left(\mathrm{Fe}^{3+}\right)$ of the indicated $\mathrm{Hbs}$ was incubated $(10 \mu \mathrm{M}$ in phosphate-buffered saline (PBS) pH 7.4) with a twofold molar excess of Hpx (from Athens Research and Technology, Inc., Athens, GA, USA). Serial UVVIS spectra were recorded with a Cary 60 UV-VIS Spectrophotometer (Agilent Technologies) and deconvoluted to follow the transition of metHb to heme-Hpx spectra.

LDL peroxidation assay. Human plasma-derived LDL was a kind gift of Dr. Lucia Rohrer, Institute of Clinical Chemistry, University Hospital of Zurich, Zurich, Switzerland. The oxidation of LDL $(0.1 \mathrm{mg} / \mathrm{ml}$ in PBS, $\mathrm{pH} 7.4)$ was measured in a closed, stirred microrespiration system with a Clark-type oxygen electrode (Unisense, Aarhus, Denmark) at $37^{\circ} \mathrm{C}$ after the injection of $\mathrm{Hb}$ in the $\mathrm{Fe}^{3+}$ form (final $\mathrm{Hb}$ concentration was $10 \mu \mathrm{M}$ heme).

Quantitative real-time RT-PCR. RT-PCR has been performed as described. ${ }^{35}$ Sequence-specific primers were as follows: HO-1 fwd $5^{\prime}$-AGGGTGATAGAAGAGGCCAAGACT-3' and rev $5^{\prime}$-TTCCACCGGACAAAGTT CATGGC-3'; ATF3 fwd $5^{\prime}$-CAAGTGCATCTTTGCCTCAA-3' and rev $5^{\prime}$-CCACCC GAGGTACAGACACT-3', SELE fwd $5^{\prime}$-AGCCCAGAGCCTTCAGTGTA-3' and rev $5^{\prime}$-AACTGGGATTTGCTGTGTCC-3'. Relative mRNA levels were calculated by the 7500 Fast System Sequence Detection Software Version 1.4 (Applied Biosystems, Rotkreuz, Switzerland) after normalization of each experimental sample to HPRT levels. The confirmation PCR experiments shown in Supplementary Figure 3 were performed with predesigned TaqMan Gene Expression Assays (Life Technologies, Basel, Switzerland). Probe set information can be obtained from the suppliers webpage using the IDs provided in the table (www.invitrogen.com).

Gene expression microarray experiments and data analysis. After washing and lysing the cells with buffer RLT, total RNA was isolated using the RNeasy Mini Kit according to the manufacturer's instructions, which included an on-column DNA digestion step (RNase-Free DNase Set, Qiagen Hombrechtikon, Switzerland). To ensure that only high-quality RNA (RNA integrity number $>7.0$ ) was used for gene expression analysis, each RNA sample was checked on a RNA Nanochip with a Bioanalyzer 2100 (Agilent Technologies). RNA was quantified spectrophotometrically with a NanoDrop ND-1000 spectrophotometer (Nanodrop Technologies, Wilmington, DE, USA). Fluorescently labeled cRNA was generated from $500 \mathrm{ng}$ total RNA with the Quick Amp Labeling Kit (Agilent Technologies) according to the manufacturer's protocol, and differential gene expression profiling was performed by competitive dual-color hybridization on Whole Human Genome Oligo Microarrays (G4112F, $4 \times 44$ K, 60-mer, Agilent Technologies). Array slides were XDR scanned and analyzed with Feature Extraction Software Version 10.7.3.1 (Agilent Technologies). Statistical analysis and visualization was performed with JMP Genomics 5.0 (SAS Institute, Boeblingen, Germany). Full gene array data were submitted to gene expression omnibus (GEO Accession \#: GSE46471).

Confocal microscopy. For confocal immunofluorescence microscopy, human endothelial cells were cultured on sterile, round 12-mm glass coverslips (Hecht-Assistent, Sondheim, Germany) coated with rat-tail collagen (BD Biosciences, San Jose, CA, USA) in 24-cluster wells. After treatment, cells were washed with PBS, pH 7.4 (Sigma Chemical Co.), before fixation with $2.5 \%$ paraformaldehyde in PBS for $15 \mathrm{~min}$. Permeabilization was performed for $5 \mathrm{~min}$ with $0.1 \%$ Triton X-100 (Sigma Chemical Co.) in PBS at room temperature. After washing, nonspecific binding sites were blocked for $1 \mathrm{~h}$ at room temperature with $10 \%$ goat serum in PBS, supplemented with $1 \%$ bovine serum albumin (Sigma Chemical $\mathrm{Co}$.). Staining for $\beta$-catenin was performed with a polyclonal rabbit antihuman $\beta$-catenin antibody (Cell Signaling Technology, Danvers, MA, USA) overnight at $4{ }^{\circ} \mathrm{C}$ at a dilution of $1: 150$ in PBS with $1 \%$ goat serum and $0.1 \%$ bovine serum albumin. A Cy3-labeled polyclonal sheep anti-rabbit antibody (IgG fraction; Abcam, Cambridge, UK) was used as a secondary antibody at a dilution of $1: 50$, and F-actin staining was performed with green fluorescently
(Alexa Fluor 488 dye) labeled Phalloidin (Invitrogen, Basel, Switzerland) at a dilution of $1: 80$. Nuclear counterstaining was performed with $10 \mathrm{mcg} / \mathrm{ml} 4,6$-diamidino-2phenylindole (DAPI; Sigma Chemical Co.). After three washes in PBS, coverslips were mounted with ProLong Gold antifade reagent-mounting medium (Molecular Probes, Invitrogen, Eugene, OR, USA). Samples were analyzed as z-stacks with a Leica SP5 confocal laser-scanning microscopy system (Leica, Heidelberg, Germany) with a HXL PL APO lambda blue $63.0 \times 1.40$ OIL UV objective.

Correlative light-electron microscopy (CLEM) and SEM analysis. For CLEM analysis, endothelial cells were cultured as described above for confocal microscopy on square-cut indium-tin-oxide (ITO) - coated $10 \times 10 \mathrm{~mm}$ glass coverslips marked for the shuttle and find solution integrated in the AxioVision Software 4.8.2 (Carl Zeiss AG, Feldbach, Switzerland). Cells were fixed with $2.5 \%$ paraformaldehyde in PBS for 15 min and directly stained (i.e., without a permeabilization step) for $\beta$-catenin and $\mathrm{F}$-actin as described for confocal microscopy. Cells were kept in PBS after staining and during all fluorescence light microscopy (FLM) imaging procedures with the coverslips placed in a sample holder especially designed for CLEM. Widefield FLM images were recorded with an Axio Imager M1 (Carl Zeiss AG) with a $20 \times$ water emersion objective and an AxioCam MRm. The samples were then prepared for electron microscopy and transferred to a Zeiss Gemini 1530 FEG SEM (Gloor Instruments AG, Uster, Switzerland). With the shuttle and find module of the AxioVision Software (Carl Zeiss $A G$ ), regions of interest were relocated and SEM imaging was performed. Overlays of the FLM and SEM pictures were performed with Adobe Photoshop Software CS3 (Adobe Systems Incorporation, San Jose, CA, USA). In some specimens, SEM analysis was performed in more detail and independent of the correlative FLM images.

For SEM analysis, cell monolayers on ITO glass substrates were fixed in 2,5\% glutharaldehyde (Sigma Aldrich, Sigma-Aldrich Chemie GmbH, Buchs, Switzerland) in PBS, washed in PBS, postfixed in $1 \% \mathrm{OsO}_{4}$ (Electron Microscopy Sciences, Hatfield, PA, USA), washed, incubated in $1 \%$ carbohydrazide (Sigma Aldrich) in distilled water, washed, stained again in $1 \%$ OsO4, and washed. After dehydration in a graded series of ethanol, the cell monolayers were plunged into liquid nitrogen and freeze dried at $-120^{\circ} \mathrm{C}$ up to $-80^{\circ} \mathrm{C}$ overnight (in a freeze etching system BAF060 from BalTEC AG, Balzers, Liechtenstein). Dried samples were warmed up to room temperature, mounted to stubs with conductive carbon cement (Leit-C, Neubauer Chemikalien, Munster, Germany), and sputter coated with $5 \mathrm{~nm}$ platinum (BalTEC sputter coater: MED 010). Microscopy was performed in a Zeiss Gemini $1530 \mathrm{FEG}$ in secondary electron mode at $5 \mathrm{kV}$.

For dual-beam microscopy (focused ion beam-SEM FIB/SEM), the cell monolayers were treated as described for SEM but were soaked with Epon/ Araldite resin (compounds from Fluka analytical (Buchs, Switzerland) and Sigma live sciences (Buchs, Switzerland)) after the dehydration. The resin was polymerized for 2 days at $60^{\circ} \mathrm{C}$, samples were trimmed and mounted and sputter coated as mentioned above. Cross-sections were performed in a Zeiss NVision 40 dual-beam microscope with gallium beam at $30 \mathrm{kV}$ and $1.5 \mathrm{nA}$. Imaging of consecutive sections were performed using back scatter electron signal at $2 \mathrm{kV}$ with an isotrope voxel size of $20 \mathrm{~nm}$. Images were aligned in Fij//ImageJ (http://fiji.sc) and visualized in Imaris (Bitplain AG, Zurich, Switzerland).

\section{Conflict of Interest}

The authors declare no conflict of interest.

Acknowledgements. This work was supported by the Swiss National Science Foundation (grants $310030 / 120658$ and $31003 \mathrm{~A} / 138500$ to DJS and PBZHP3133422 to CAS), the University of Zurich Research Priority Program 'Integrative Human Physiology', the Swiss Federal Commission for Technology and Innovation (CTI), and the 'Patient Blood Management' Program of the Department of Health of the Canton of Zurich, Switzerland.

1. Schaer DJ, Buehler PW, Alayash Al, Belcher JD, Vercellotti GM. Hemolysis and free hemoglobin revisited: exploring hemoglobin and hemin scavengers as a novel class of therapeutic proteins. Blood 2013; 121: 1276-1284.

2. Rother RP, Bell L, Hillmen P, Gladwin MT. The clinical sequelae of intravascular hemolysis and extracellular plasma hemoglobin: a novel mechanism of human disease. JAMA 2005; 293: 1653-1662. 
3. Boyle JJ, Johns M, Kampfer T, Nguyen AT, Game L, Schaer DJ et al. Activating transcription factor 1 directs Mhem atheroprotective macrophages through coordinated iron handling and foam cell protection. Circ Res 2012; 110: 20-33.

4. Kaempfer T, Duerst E, Gehrig P, Roschitzki B, Rutishauser D, Grossmann J et al. Extracellular hemoglobin polarizes the macrophage proteome toward $\mathrm{Hb}$-clearance, enhanced antioxidant capacity and suppressed HLA class 2 expression. J Proteome Res 2011; 10: 2397-2408.

5. Andersen CB, Torvund-Jensen M, Nielsen MJ, de Oliveira CL, Hersleth HP, Andersen NH et al. Structure of the haptoglobin-haemoglobin complex. Nature 2012; 489: 456-459.

6. Kristiansen M, Graversen JH, Jacobsen C, Sonne O, Hoffman HJ, Law SK et al. Identification of the haemoglobin scavenger receptor. Nature 2001; 409: 198-201.

7. Schaer CA, Vallelian F, Imhof A, Schoedon G, Schaer DJ. CD163-expressing monocytes constitute an endotoxin-sensitive $\mathrm{Hb}$ clearance compartment within the vascular system. J Leukoc Biol 2007; 82: 106-110.

8. Boretti FS, Buehler PW, D'Agnillo F, Kluge K, Glaus T, Butt Ol et al. Sequestration of extracellular hemoglobin within a haptoglobin complex decreases its hypertensive and oxidative effects in dogs and guinea pigs. J Clin Invest 2009; 119: 2271-2280.

9. Baek JH, D'Agnillo F, Vallelian F, Pereira CP, Williams MC, Jia Y et al. Hemoglobin-driven pathophysiology is an in vivo consequence of the red blood cell storage lesion that can be attenuated in guinea pigs by haptoglobin therapy. J Clin Invest 2012; 122: 1444-1458.

10. Buehler PW, D'Agnillo F, Schaer DJ. Hemoglobin-based oxygen carriers: from mechanisms of toxicity and clearance to rational drug design. Trends Mol Med 2010; 16: 447-457.

11. Cooper CE, Schaer DJ, Buehler PW, Wilson MT, Reeder BJ, Silkstone G et al. Haptoglobin binding stabilizes hemoglobin ferryl iron and the globin radical on tyrosine beta145. Antioxidants Redox Signaling 2012; 18: 2264-2273.

12. Niethammer P, Grabher C, Look AT, Mitchison TJ. A tissue-scale gradient of hydrogen peroxide mediates rapid wound detection in zebrafish. Nature 2009; 459: 996-999.

13. Chance $B$, Sies $H$, Boveris $A$. Hydroperoxide metabolism in mammalian organs. Physiological reviews 1979; 59: 527-605.

14. Weiss SJ, Young J, LoBuglio AF, Slivka A, Nimeh NF. Role of hydrogen peroxide in neutrophil-mediated destruction of cultured endothelial cells. J Clin Invest 1981; 68: 714-721.

15. Alayash Al. Oxygen therapeutics: can we tame haemoglobin? Nature reviews Drug discovery 2004; 3: 152-159.

16. Jeney V, Balla J, Yachie A, Varga Z, Vercellotti GM, Eaton JW et al. Pro-oxidant and cytotoxic effects of circulating heme. Blood 2002; 100: 879-887.

17. Wagener FA, Eggert A, Boerman OC, Oyen WJ, Verhofstad A, Abraham NG et al. Heme is a potent inducer of inflammation in mice and is counteracted by heme oxygenase. Blood 2001; 98: 1802-1811.

18. D'Agnillo F, Alayash Al. Redox cycling of diaspirin cross-linked hemoglobin induces G2/M arrest and apoptosis in cultured endothelial cells. Blood 2001; 98: 3315-3323.

19. Banerjee S, Jia Y, Siburt CJ, Abraham B, Wood F, Bonaventura C et al. Haptoglobin alters oxygenation and oxidation of hemoglobin and decreases propagation of peroxide-induced oxidative reactions. Free Radic Biol Med 2012; 53: 1317-1326.

20. Schaer DJ, Buehler PW. Cell-free hemoglobin and its scavenger proteins: new disease models leading the way to targeted therapies. Cold Spring Harb Perspect Med 2013; 3: 6 .

21. Kaczara P, Sarna T, Burke JM. Dynamics of $\mathrm{H} 2 \mathrm{O} 2$ availability to ARPE-19 cultures in models of oxidative stress. Free Radic Biol Med 2010; 48: 1064-1070.
22. Choe Y, Yu JY, Son YO, Park SM, Kim JG, Shi X et al. Continuously generated H2O2 stimulates the proliferation and osteoblastic differentiation of human periodontal ligament fibroblasts. J Cell Biochem 2012; 113: 1426-1436.

23. Buehler PW, Abraham B, Vallelian F, Linnemayr C, Pereira CP, Cipollo JF et al. Haptoglobin preserves the CD163 hemoglobin scavenger pathway by shielding hemoglobin from peroxidative modification. Blood 2009; 113: 2578-2586.

24. Jia Y, Buehler PW, Boykins RA, Venable RM, Alayash Al. Structural basis of peroxidemediated changes in human hemoglobin: a novel oxidative pathway. J Biol Chem 2007; 282: 4894-4907.

25. Vallelian F, Pimenova T, Pereira CP, Abraham B, Mikolajczyk MG, Schoedon G et al. The reaction of hydrogen peroxide with hemoglobin induces extensive alpha-globin crosslinking and impairs the interaction of hemoglobin with endogenous scavenger pathways. Free Radic Biol Med 2008; 45: 1150-1158.

26. Widmer CC, Pereira CP, Gehrig P, Vallelian F, Schoedon G, Buehler PW et al. Hemoglobin can attenuate hydrogen peroxide-induced oxidative stress by acting as an antioxidative peroxidase. Antioxidants Redox Signaling 2010; 12: 185-198.

27. Chen BP, Wolfgang CD, Hai T. Analysis of ATF3, a transcription factor induced by physiological stresses and modulated by gadd153/Chop10. Mol Cell Biol 1996; 16: $1157-1168$

28. Alayash Al. Haptoglobin: old protein with new functions. Int J Clin Chem 2011; 412: 493-498.

29. Balla G, Jacob HS, Eaton JW, Belcher JD, Vercellotti GM. Hemin: a possible physiological mediator of low density lipoprotein oxidation and endothelial injury. Arterioscler Thromb J Vasc Biol 1991; 11: 1700-1711.

30. Pimenova T, Pereira CP, Gehrig P, Buehler PW, Schaer DJ, Zenobi R. Quantitative mass spectrometry defines an oxidative hotspot in hemoglobin that is specifically protected by haptoglobin. J Proteome Res 2010; 9: 4061-4070.

31. Silva G, Jeney V, Chora A, Larsen R, Balla J, Soares MP. Oxidized hemoglobin is an endogenous proinflammatory agonist that targets vascular endothelial cells. J Biol Chem 2009; 284: 29582-29595.

32. Balla J, Vercellotti GM, Jeney V, Yachie A, Varga Z, Jacob HS et al. Heme, heme oxygenase, and ferritin: how the vascular endothelium survives (and dies) in an iron-rich environment. Antioxidants Redox Signaling 2007; 9: 2119-2137.

33. Miller YI, Altamentova SM, Shaklai N. Oxidation of low-density lipoprotein by hemoglobin stems from a heme-initiated globin radical: antioxidant role of haptoglobin. Biochemistry 1997; 36: 12189-12198

34. Lipiski M, Deuel JW, Baek JH, Engelsberger WR, Buehler PW, Schaer DJ. Human Hp1-1 and Hp2-2 phenotype-specific haptoglobin therapeutics are both effective in vitro and in guinea pigs to attenuate hemoglobin toxicity. Antioxidants Redox Signaling 2013 Mar 28.

35. Schaer CA, Schoedon G, Imhof A, Kurrer MO, Schaer DJ. Constitutive endocytosis of CD163 mediates hemoglobin-heme uptake and determines the noninflammatory and protective transcriptional response of macrophages to hemoglobin. Circ Res 2006; 99: 943-950.

(c) (i) (3)(-) This work is licensed under a Creative Commons Attribution-NonCommercial-ShareAlike 3.0 Unported License. To view a copy of this license, visit http://creativecommons. org/licenses/by-nc-sa/3.0/

Supplementary Information accompanies this paper on Cell Death and Differentiation website (http://www.nature.com/cdd) 